\title{
Young Children's Use of Gender for Inductive Generalizations about Biological and Behavioral Characteristics: The Influence of Gender Categories and Gender Stereotypes
}

\author{
Bradford H. Pillow ${ }^{1}$, Cara Allen ${ }^{1}$, Natalie Low $^{1} \&$ Taneisha Vilma ${ }^{1}$ \\ ${ }^{1}$ Department of Psychology, Northern Illinois University, De Kalb, United States \\ Correspondence: Bradford H. Pillow, Department of Psychology, Northern Illinois University, De Kalb, IL \\ 60115, United States. Tel: 1-815-753-7079. Email: pillow@niu.edu
}

Received: June 5, 2019 Accepted: June 28, 2019 Online Published: July 8, 2019

doi:10.5539/jedp.v9n2p37

URL: http://doi.org/10.5539/jedp.v9n2p37

\begin{abstract}
Using a triad inductive reasoning task, we examined the influence of gender category information, gender stereotypes, and gender salience on young children's $(\mathrm{N}=72 ; 36$ to 69 months of age) generalizations concerning novel biological and behavioral characteristics. Prior to the inductive generalization task, children heard vignettes in which a teacher either engaged in gender stereotyping (Stereotype condition), grouped children according to gender (Salience condition), or grouped children in a gender-neutral manner (Neutral condition). Children generalized on the basis of gender more often in the Stereotype condition than in the Neutral condition, but older children made gender-based inductions at above chance levels in the Neutral condition and for behavioral traits in the Salience condition. Stereotyping influenced gender-based reasoning, but did not appear to be necessary among older preschool children.
\end{abstract}

Keywords: induction, gender stereotypes, social categories

\section{Introduction}

Knowledge about gender categories and gender stereotypes may influence children's reasoning about the characteristics of other people. For example, young children may use gender information to infer another child's toy preferences or biological properties, and to predict an infant's future traits and behaviors (Gelman, Collman, \& Maccoby, 1986; Martin, 1989; Taylor, 1996; Taylor, Rhodes, \& Gelman, 2009). The present study examined the influence of gender category information, gender stereotypes, and gender salience on young children's reasoning about others' behavioral and biological characteristics.

By early childhood, category information influences children's reasoning. Using a triad task, Gelman and Markman (1986) investigated children's use of category membership versus perceptual similarity for making inductive generalizations. Four-year-olds were presented with sets of three pictures, including two test items belonging to different categories (e.g., a flamingo and a bat) and a target (e.g., a blackbird). The target belonged to the same category as one test item (e.g., the blackbird and flamingo were both labeled as birds), but the two differed in appearance, whereas the target looked similar to the second test item (e.g., the bat), but belonged to a different category. Children were taught an unfamiliar property for each test item (e.g., the bird (flamingo) feeds its babies mashed up food; the bat feeds its babies milk), and were asked which property was characteristic of the target. Children generalized on the basis of shared category membership more often than similarity in appearance (e.g., reasoning that the blackbird feeds its babies mashed up food like the flamingo). Subsequent research indicates that children often use category labels as a basis for induction, but children's reliance on category information versus perceptual similarity varies depending on the types of categories and items presented (Badger \& Shapiro, 2015; Gelman \& Davidson, 2013; Long, Lu, Zhang, Li, \& Deak, 2011; Sloutsky, Kloos, \& Fisher, 2007). Thus, inductive generalization appears somewhat variable during early childhood.

Children also generalize on the basis of social categories, though again, the tendency to generalize depends on the categories presented, children's experience with them, and the property in question. Children's attention to ethnicity, race, and gender appears to vary according to children's age and social and cultural context (e.g., Birnbaum, Deeb, Segall, Ben-Eliyahu, \& Diesendruck, 2010; Kinzler, Shutts, \& Correll, 2010). Among 4-year-olds in the United Stated, Gelman et al. (1986) found that children attributed novel biological properties and 
familiar behaviors on the basis of gender category membership more than similarity in appearance. For example, when taught that a boy had andro in his blood and that a girl had estro in her blood, children inferred that another boy, who resembled the girl in outward appearance, also had andro in his blood. When told that a girl played with dolls and a boy played with trucks, children concluded that another girl, who resembled the boy, also played with dolls. Gelman et al. (1986) presented a mix of novel and familiar items. The novel items were biological properties that would be unfamiliar to young children. The familiar items included both biological and behavioral characteristics, with the behavioral items corresponding to familiar gender stereotypes, such as "This boy play with trucks and does boy things. This girl plays with dolls and does girl things.", and the biological items including items indicative of sex differences, such as "This boy will grow up to be a daddy. This girl will grow up to be a mommy". Including gender-stereotyped items may have encouraged stereotypical responses for familiar items and gender-based inductions for unfamiliar items. In contrast, in one experiment Pillow, Pearson, and Allen (2015) presented novel biological properties similar to those used by Gelman et al. (1986), and gender-neutral behaviors (such as "always works hard on puzzles" and "Always cleans up toys at school"), and found that 3- to 5-year-olds did not generalize either the biological properties or behaviors on the basis of gender more than appearance.

Because gender stereotypes may influence children's social judgments, when assessing category-based induction it is important to distinguish the impacts of stereotyping and categorization. Thus, in a second experiment Pillow et al. (2015) presented one group of 3- to 5-year-old children stereotyped behaviors and novel biological properties and another group novel behaviors and novel biological properties. Children who were asked to generalize stereotyped behaviors generalized both behaviors and biological properties on the basis of gender more than appearance; however, children who were asked to generalize neutral behaviors generalized on the basis of gender and appearance equally. Reasoning about familiar gender-stereotyped behaviors appeared to increase children's tendency to make gender-based inductions concerning novel biological properties. Because Pillow et al. (2015) presented gender stereotypes within the behavioral items for the inductive generalization task, their procedure assessed the influence of those stereotypes on children's reasoning about novel biological properties presented as separate items, but did not assess the impact of stereotypes on children's reasoning about novel behavioral characteristics.

In the present study we attempted to replicate and extend Pillow et al.'s (2015) finding concerning the influence of stereotypes on inductive generalization. To separate gender stereotypes from the inductive generalization task, we presented stereotypes via brief vignettes prior to a triad task. We sought to distinguish the influence of gender categories, gender stereotypes, and gender salience on children's inductive generalizations of novel biological and behavioral characteristics. According to Developmental Intergroup Theory (Bigler \& Liben, 2007), both adult labeling of social categories and adult attributions about social categories are powerful influences on children's social attitudes. Bigler and Liben (2007) suggest that social experiences that highlight group distinctions or communicate stereotypes will increase children's attention to group distinctions and promote stereotyping. For example, adult references to gender and gender stereotypes should increase children's attention to gender and information associated with gender. To examine the influence of adult messages about gender on children's reasoning, we presented vignettes that were set in a classroom. In each vignette, a teacher greeted students and then assigned groups of children to play with different materials in different locations. In the Stereotype condition, the teacher assigned girls to play with stereotypically feminine toys on one side of the room and boys to play with stereotypically masculine toys on the other side of the room. In the Salience condition, the teacher assigned girls and boys to play with different gender-neutral materials. In the Neutral condition, the teacher assigned two-mixed gender groups to play with different gender-neutral materials. Gender was mentioned during the vignettes for the Stereotype and Salience conditions, but not the Neutral condition. However, because gender was mentioned during the inductive generalization task for all three conditions, gender category information was present across conditions.

We predicted that (a) children would generalize both biological and behavioral characteristics on the basis on gender more frequently in the Stereotype condition than in the Neutral condition, and (b) children would respond on the basis of gender at above chance levels in the Stereotype condition but not in the Neutral condition. The Salience condition was included to examine whether stereotyping is necessary for gender-based induction, or whether simply drawing children's attention to gender via adult labeling is sufficient.

\section{Method}

\subsection{Participants}

Seventy-two preschool children participated. Children were divided into a younger group (mean age 3 years, 8 months; age range 3 years to 4 years, 6 months; 18 boys and 18 girls) and an older group (mean age 5 years, 1 
month; age range 4 years, 7 months to 5 years, 9 months; 19 boys and 17 girls), with equal number of younger and older children participating in each of three between-subjects conditions (Stereotype, Salience, and Neutral). The children were students at preschools in suburban or rural towns in northern Illinois. Children were predominantly European-American. All children participated with informed written parental consent.

\subsection{Materials}

In each condition two pictures of a school classroom were used to depict events that either presented gender stereotypes, emphasized gender without mentioning stereotypes, or presented gender-neutral information (see Appendix for examples). Each picture included a classroom with a teacher, two groups of four children, two sets of five toys or art materials, and two sets of four chairs. In the Stereotype condition, the sets of toys were footballs and dolls in one picture, and trucks and princess dresses in the other. The teacher was standing in the center of the room with four boys to one side and four girls on the other side. The footballs or trucks were near a group of chairs in front of the boys and the dolls or dresses were near another group of chairs in front of the girls. In the Salience condition, the pictures were similar, except that the toys were crayons and paints in one picture and Legos and blocks in the other. The pictures in the Neutral condition were similar to those in the salience condition, except that each group of children included two girls and two boys.

For the inductive generalization task, 8 sets of pictures were presented. The pictures were computer-generated images of children cropped below the shoulders. Each set included three pictures. Two pictures (the test pictures) were arranged side by side on the same page. The third picture (the target) was on a separate page below the first two pictures. The two children in the test pictures differed in shirt color, facial features, hair color and length, and eye color. The target child had the same hair color, eye color, and facial features as one of the two test children, but differed from both of the test children in hair length and shirt color. To make the individuals in each of the 8 triads distinct, hair color, hair style, eye color, facial features, and shirt color were varied across the 8 set of images.

Eight biological characteristics and eight behavioral characteristics were presented as feature of the test children. The behavioral characteristics described either activity or toy preferences using English-sounding nonsense words: "wants a mova for his birthday", "wants a numa for her birthday", "likes to play a game called tedge", "likes to play with a game called setch", "likes to pretend she's a nath", "likes to pretend he's a fank", "plays with samas", and "plays with noyas". The biological characteristics were labeled with shortened versions of scientific terms (e.g., neutros for neutrofils, telos for telomeres, etc.). The test children were described as having the following characteristics in either their body or blood: telos, brevies, neutros, fibro, lattis, sarto, transfa, and prothro.

\subsection{Procedure}

Each condition began with a description of a classroom event in which a teacher assigned two groups of children to play with a different set of materials, followed by four trials of the inductive generalization task. Then a second classroom event was described, and there were four more inductive generalization trials.

In the Stereotype condition, participant children were shown one of the two stereotype classroom pictures and told, "One morning at school, the teacher told the children there were some new toys to play with. She said, "Good morning children. I have some new toys. There are some new footballs/trucks and some new dolls/princess costumes. Boys like football/trucks. So the boys can play with the footballs/trucks over here. Girls like to play with dolls/princess costumes. So the girls can play with the dolls/princess costumes over here." Then the experimenter stated "The teacher thinks that boys like football/trucks and girls like dolls/princess costumes." Because the majority of preschool teachers are women, the teacher was depicted as female. The order of mention stereotypically masculine or feminine toys and of boys and girls was counterbalanced across children. Next, children received four inductive generalization trials. Biological and behavioral trials alternated, with half of the participants beginning with a biological trial and half with a behavioral trial. Then the second classroom picture was presented, followed by the four more inductive generalization trials. The second classroom picture was the same as the first, but with different toys or play materials (e.g, footballs and dolls in the first picture, but trucks and princess costumes in the second). The order of presentation of the two classroom pictures was counterbalanced across children.

When the salience classroom picture was presented in the Salience condition, children were told, "One morning at school, the teacher told the children there were some new things to play with. She said, "Good morning children. I have some new things. There are some new paints/legos and some new crayons/blocks. Boys and girls can play with them today. The girls can play with the paints/legos over here. The boys can play with the crayons/blocks over here." The experimenter stated "The teacher thinks that girls and boys like paints/legos and crayons/blocks." Otherwise, the procedure was the same as in the Stereotype condition. 
In the Neutral condition, a neutral classroom picture was presented, and children were told, "One morning at school, the teacher told the children there were some new things to play with. She said, "Good morning children. I have some new things. There are some new paints/Legos and some new crayons/blocks. Children can play with them today. Some children can play with the paints/Legos over here. Some children can play with the crayons/blocks over here." The experimenter then said, "The teacher thinks children like to play with paints/Legos and crayons/blocks." The remainder of the procedure was the same as in the other two conditions, with the exception that order of mention of boys and girls for the classroom pictures did not need to be counterbalanced because gender was not mentioned.

There were eight trials for the inductive generalization task. On each trial the experimenter presented a set of three pictures and taught children either a behavioral or biological characteristic for each of the two test images (test child A and test child B). Then children were asked if the target child had the same characteristic as test child A or test child B. In each triad, the target child visually resembled either test child A or test child B, but was labeled as the same gender as the other child, who differed from the target visually. For example, on a biological trial when the test pictures were presented children were told, "Here's a boy. And here's a girl. This boy has fibro in his blood. This girl has neutros in her blood." Then the target picture was presented below the test pictures, and children were asked "Now here's another boy. What does this boy have in his blood? Does he have fibro in his blood like this boy? Or does he have neutro in his blood like this girl?" The procedure was similar for behavioral trials. For example, "Here's a girl. And here's a boy. This girl plays with samas. This boy plays with noyas. Now here's another girl. What does this girl do? Does she play with samas like this girl? Or does she play with noyas like this boy?" Each biological or behavior characteristic was associated with a girl test picture for half of the participants and with a boy test picture for the other half.

Biological and behavioral trials were presented in an alternating sequence, with half of the children in each condition beginning with a biological trial, and half beginning with a behavioral trial. The order of mention of the boy and girl in the test pictures alternated over trials. The order of mention of the boy and girl in the test question matched the order used in the description of the test pictures, and thus also alternated over trials. In addition, for half of the trials of each type, the target child was a boy and for the other half the target was a girl.

\section{Results}

Each child was given scores from 0-4 for biological trials and 0-4 for behavioral trials, corresponding to the number of gender-based responses made for each type of trait. Means are presented in Table 1. Results were analyzed with a $2 \times 3 \times 2$ (Age Group x Condition x Trait) ANOVA with Trait as a repeated measures factor, followed by t-tests comparing performance to chance expectations. The ANOVA yielded significant effects of Age Group, $F(1,66)=11.58, p=.001$, partial $\eta^{2}=0.149$, and Condition, $F(2,66)=6.27, p=.033$, partial $\eta^{2}=.098$. Older children gave gender-based responses significantly more often than did younger children, and children gave more gender-based responses in the Stereotype condition than in either the Salience condition, $t(46)=2.19, p$ $=.034$, or the Neutral condition, $t(46)=2.34, p=.024$. Furthermore, in the Stereotype condition both age groups made gender-based attributions for both biological and behavioral traits significantly more often than would be expected by chance (younger children: biology: $t(11)=2.24, p=.046$, behavior: $t(11)=2.24, p=.046$; older children: biology: $t(11)=2.42, p=.034$, behavior: $t(11)=7.09, p<.001)$. In the Salience condition, younger children did not perform significantly different from chance for either biological or behavioral traits. Older children attributed behavioral traits on the basis of gender significantly more often than would be expected by chance, $t(11)=2.271, p=.043$, but did not perform differently from chance for biological traits. In the Neutral condition, younger children did not perform significantly different from chance for either biological or behavioral traits. Older children attributed both biological, $t(11)=3.08, p=.01$, and behavioral traits, $t(11)=2.97, p=.013$, on the basis of gender more frequently than would be expected by chance. 
Table 1. Mean number of gender-based responses by Age, Condition, and Item Type

\begin{tabular}{|c|c|c|c|c|c|c|c|c|}
\hline & \multicolumn{4}{|c|}{ Younger } & \multicolumn{4}{|c|}{ Older } \\
\hline & \multicolumn{2}{|l|}{ Behavior } & \multicolumn{2}{|c|}{ Biology } & \multicolumn{2}{|c|}{ Behavior } & \multicolumn{2}{|c|}{ Biology } \\
\hline & $\mathrm{M}$ & $\mathrm{SD}$ & $\mathrm{M}$ & SD & M & SD & $\mathrm{M}$ & $\mathrm{SD}$ \\
\hline Stereotype & 2.53 & 0.90 & 2.58 & 0.90 & 2.83 & 1.19 & 3.33 & 0.65 \\
\hline Salience & 1.92 & 1.00 & 1.75 & 1.29 & 2.75 & 1.14 & 2.33 & 1.44 \\
\hline Neutral & 1.75 & 1.14 & 1.67 & 1.15 & 2.67 & 0.78 & 2.83 & 0.94 \\
\hline
\end{tabular}

Note. Maximum possible mean per cell $=4.00$.

\section{Discussion}

We examined the influence of gender category information, gender stereotypes, and gender salience on young children's inductive generalizations concerning novel biological and behavioral characteristics. The inductive generalization task was preceded by vignettes in which a teacher either engaged in gender stereotyping, grouped children according to gender, or grouped children in a gender-neutral manner. We expected greater gender-based induction following exposure to stereotypes. The results were partly consistent with our predictions. As predicted, children generalized on the basis of gender more often in the Stereotype condition than in the Neutral condition, and also made such generalizations at above chance levels. However, contrary to expectations, older children made gender-based inductions for biological and behavioral traits in the Neutral condition and for behavioral traits in the Salience condition. Thus, some gender-based reasoning occurred even in the absence of stereotyping. Stereotyping seemed to influence gender-based reasoning, but did not appear to be necessary, at least among older preschool children.

According to Developmental Intergroup Theory (Bigler \& Liben, 2007), both cognitive processes, such as categorization, and social processes, such as explicit labeling of categories and stereotyping, contribute to children's social attitudes. The present results are consistent with this model; however, performance differed by age. In all three conditions, the gender labels presented in the inductive generalization task provided a cue to categorical relations among the target and test pictures. Older children's gender-based generalizations in the Neutral condition suggest that gender labeling and category knowledge influenced older children's judgments, though performance was less consistent in the Salience condition despite the increased emphasis on gender in the classroom vignettes. Gelman et al. (1986) suggested that gender category knowledge guides children's reasoning. The older children in the present study were similar in age to the participants in Gelman et al.'s (1986) study, and performance in the Neutral condition is consistent with their finding that 4-year-olds often generalized biological characteristics on the basis of gender rather than similarity in appearance. Older children's pattern of generalizations in the Neutral condition differs from the random performance reported by Pillow et al. (2015), but younger children's chance performance in both the Neutral and Salience conditions is consistent with Pillow et al.'s (2015) results. In the Stereotype condition, after hearing vignettes in which a teacher labeled and stereotyped boys and girls, both age groups frequently made gender-based inferences. Children's gender-based generalizations in the Stereotype condition are consistent with Developmental Intergroup Theory and with the results reported by Pillow et al. (2015). The Stereotype condition vignettes may have been particularly effective at eliciting gender-based inductions because: (a) the vignettes contained gender stereotypes that were explicitly expressed by a trusted adult authority, (b) the stereotypes should have been familiar to children and may have activated children's existing knowledge about gender and gender differences, and (c) the stereotypes were themselves were explicit generalizations about gender that may have encouraged further generalization.

The age differences in performance are consistent with the results of some previous studies of inductive generalization. In the present study, compared to younger children ( 3 to 4.5 years old), older preschool children ( 4.5 to 5 years old) used gender as a basis for induction more consistently and more generally across contexts (Stereotype, Salience, and Neutral condition) and domains (biological and behavioral items). Using novel categories, Badger and Shapiro (2015) reported a shift in patterns of induction, with 5- to 6-year-olds mostly preferring perceptual similarity as a basis for induction, and 7- to 9-year-olds increasingly preferring category membership. Likewise, when children had been taught novel artificial categories, Sloutsky, Deng, Fisher, and Kloos (2015) also reported a shift from perceptually-based to conceptually-based induction around 7 years of age. With familiar categories that young children could identify readily without hearing labels, Godwin and Fisher (2015) found that 5-year-olds, but not 3- to 4-year-olds, made categorical rather than perceptual generalizations. 
When presented category labels in the absence of perceptual information, most 5- and 6-year-olds made category-based inferences, but most 4-year-olds did not (Fisher, Matlen, \& Godwin, 2011). Although by 3-years of age children are familiar with gender categories, as well as stereotypes regarding toys, activities, clothing, and some social behaviors (Martin \& Ruble, 2009), children's performance in the present study suggests that gender categories become more central to children's reasoning during the later preschool years. In the triad inductive generalization task children might construe the novel facts as referring to either unique individual attributes, group properties shared by members of particular gender or age group, or general human characteristics. Younger children's inconsistent performance in the Salience and Neutral conditions may reflect, in part, variability in their understanding of this novel information. Gender match responses may have been less likely to the extent that children perceived the two targets either as two generic human exemplars or as two unique individuals. As peer experience and gender knowledge increase, older preschool children may attend to gender categories more both during induction tasks and in everyday social interactions.

According to Developmental Intergroup Theory, children's tendency to categorize individuals into groups leads to the formation of stereotypes (Bigler \& Liben, 2007). In addition, the present results suggest that stereotype knowledge may contribute to children's attention to and use of social categories when drawing inferences about others. The resulting category-based generalizations may reinforce existing stereotypes or engender new stereotypes. Thus, there may be dynamic, bidirectional developmental relationships among categorization, stereotyping, and induction.

\section{Acknowledgements}

We thank the children, parents, teachers who participated in this study.

\section{References}

Badger, J. R., \& Shapiro, L. R. (2015). Category structure affects the developmental trajectory of children's inductive inferences for both natural kinds and artefacts. Thinking \& Reasoning, 21, 206-229. https://doi.org/10.1080/13546783.2014.952338

Bigler, R. S., \& Liben, L. S. (2007). Developmental intergroup theory: Explaining and reducing children's social stereotyping and prejudice. Current in Psychological Science, 16, 162-166. https://doi.org/10.1111/j.1467-8721.2007.00496.x

Birnbaum, D., Deeb, I., Segall, G., Benliyahu, A., \& Diesendruck, G. (2010). The development of social essentialism: The case of Israeli children's inferences about Jews and Arabs. Child Development, 81, 757-777. https://doi.org/10.1111/j.1467-8624.2010.01432.x

Fisher, A. V., Matlen, B. J., \& Godwin, K. E. (2011). Semantic similarity of labels and inductive generalization: Taking a second look. Cognition, 118, 432-438. https://doi.org/10.1016/j.cognition.2010.12.008

Gelman, S. A., Collman, P., \& Maccoby, E. E. (1986). Inferring categories from properties vs. inferring properties from categories: The case of gender. Child Development, 57, 396-404. https://doi.org/10.2307/1130595

Gelman, S. A., \& Davidson, N. S. (2013). Conceptual influences on category-based induction. Cognitive Psychology, 66, 327-353. https://doi.org/10.1016/j.cogpsych.2013.02.001

Gelman, S. A., \& Markman, E. M. (1986). Categories and induction in young children. Cognition, 23, 183-209. https://doi.org/10.1016/0010-0277(86)90034-X

Godwin, K. E., \& Fisher, A. V. (2015). Inductive generalization with familiar categories: Developmental changes in children's reliance on perceptual similarity and kind information. Frontiers in Psychology, 6, 1-15. https://doi.org/10.3389/fpsyg.2015.00897

Kinzler, K. D., Shutts, K., \& Correll, J. (2010). Priorities in social categories. European Journal of Social Psychology, 40, 581-592. https://doi.org/10.1002/ejsp.739

Long, C., Lu, X., Zhang, L., Li, H., \& Deák, G. O. (2011). Category label effects on Chinese children's inductive inferences: Modulation by perceptual detail and category specificity. Journal of Experimental Child Psychology, 111, 230-245. https://doi.org/10.1016/j.jecp.2011.08.010

Martin, C. L. (1989). Children's use of gender-related information in making social judgments. Developmental Psychology, 25, 80-88. https://www.ulib.niu.edu:2564/doiLanding?doi=10.1037\%2F0012-1649.25.1.80

Martin, C. L., \& Ruble, D. N. (2009). Patterns of gender development. Annual Review of Psychology, 61, 353-381. https://doi.org/10.1146/annurev.psych.093008.100511 
Pillow, B. H., Pearson, R. M., \& Allen, C. (2015). Young children's inductive generalizations about social categories: When is gender essential? Merrill-Palmer Quarterly, 61, 441-467. https://doi.org/10.13110/merrpalmquar1982.61.4.0441

Sloutsky, V. M., Kloos, H., \& Fisher, A. V. (2007). When looks are everything: Appearance similarity versus kind information in early induction. Psychological Science, $18, \quad 179-185$. https://doi.org/10.1111/j.1467-9280.2007.01869.x

Sloutsky, V. M., Deng, W., Fisher, A. V., \& Kloos, H. (2015). Conceptual influences on induction: A case for a late onset. Cognitive Psychology, 82, 1-31. https://doi.org/10.1016/j.cogpsych.2015.08.005

Taylor, M. (1996). The development of children's beliefs about social and biological aspects of gender differences. Child Development, 67, 1555-1571. https://doi.org/10.1111/j.1467-8624.1996.tb01814.x

Taylor, M. G., Rhodes, M., \& Gelman, S. A. (2009). Boys will be boys, cows will be cows: Children's essentialist reasoning about gender and animal development. Child Development, 80, 461-481. https://doi.org/10.1111/j.1467-8624.2009.01272.x 


\section{Appendix.}

Examples of Pictures

\section{Classroom: Stereotype condition}

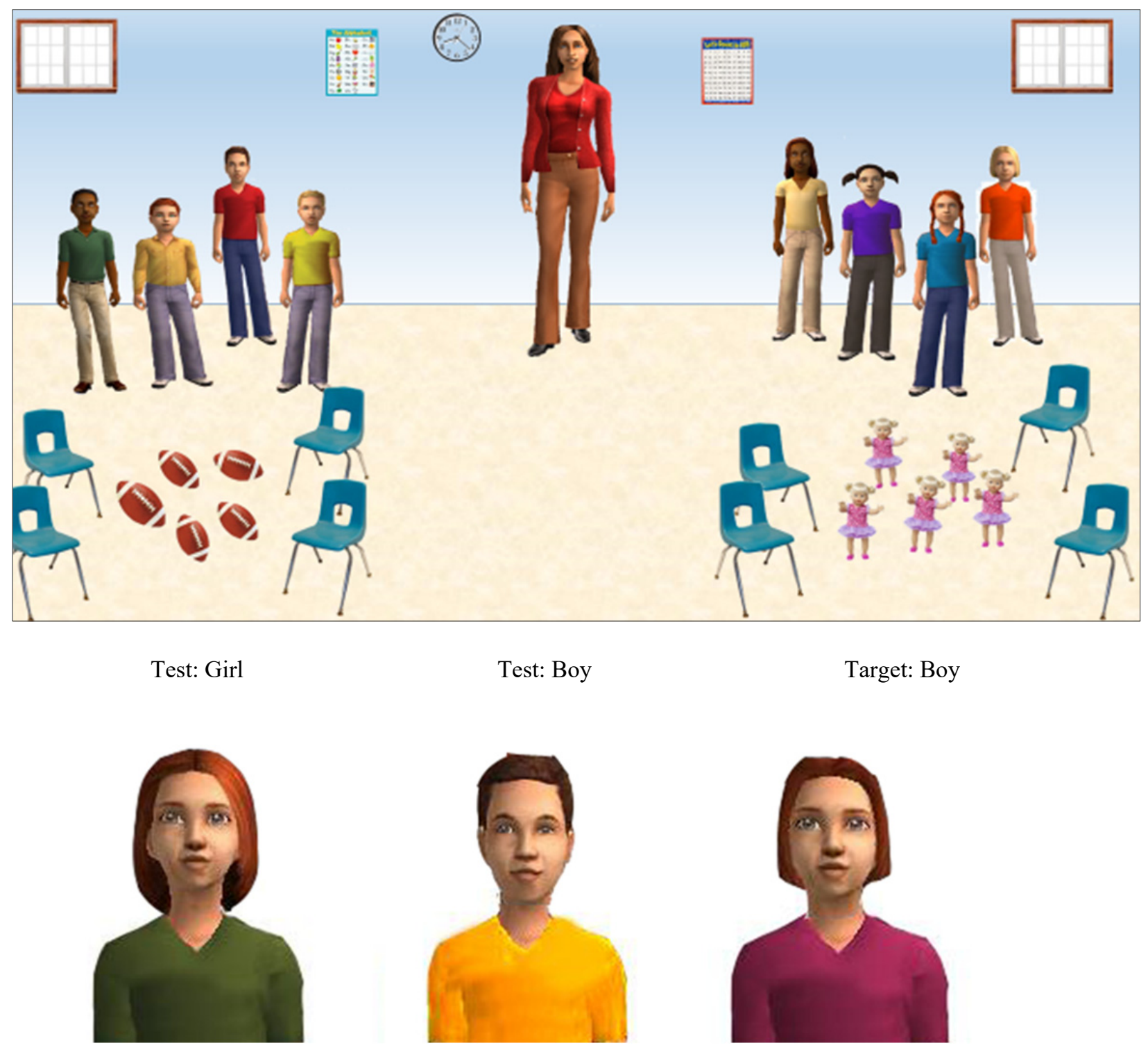

\section{Copyrights}

Copyright for this article is retained by the author(s), with first publication rights granted to the journal.

This is an open-access article distributed under the terms and conditions of the Creative Commons Attribution license (http://creativecommons.org/licenses/by/4.0/). 